\title{
Mapping of Quantitative Trait Loci Associated with Concentrations of Five Trace Metal Elements in Rice (Oryza sativa)
}

\author{
Fenglin Huang ${ }^{1,2,3}$, Xiangjin Wei ${ }^{2}$, Jiwai He ${ }^{1,2}$, Zhonghua Sheng ${ }^{2}$, Gaoneng Shao', Jianlong Wang', Shaoqing Tang ${ }^{2}$, \\ Shengpin $\mathrm{Xia}^{3}$, Yinghui $\mathrm{Xiao}^{1}$ and Peisong $\mathrm{Hu}^{1,2^{*}}$ \\ ${ }^{1}$ College of Agronomy, Hunan Agricultural University, Changsha, 410128, China \\ ${ }^{2}$ State Key Laboratory of Rice Biology, China National Rice Research Institute, Hangzhou, 310006, China \\ ${ }^{3}$ Hunan Rice Research Institute, Hunan Academy of Agricultural Science, Changsha, 410125, China \\ *For correspondence: peisonghu@126.com; hupeisong@caas.cn
}

\begin{abstract}
Trace metal element concentrations in rice (Oryza sativa L.) have great effects on the health of human being. In this study, QTLs for the concentrations of $\mathrm{Cd}, \mathrm{Cu}, \mathrm{Fe}, \mathrm{Mn}$ and $\mathrm{Zn}$ in brown rice were identified using a recombinant inbred lines (RIL) population. A total of 22 QTLs for the concentrations of $\mathrm{Cd}, \mathrm{Cu}, \mathrm{Fe}, \mathrm{Mn}$ and $\mathrm{Zn}$ in brown rice were identified with 204 recombinant inbred lines (RILs), including $q C d 5$ for pot cultivation (PC) with Cd stress and paddy field cultivation (FC) trials in Hangzhou, 9 for PC trial only, and 13 for FC trial only. The phenotypic variance explained by a single QTL ranged as 4.69.9\% and 2.8-10.4\% in PC and FC trials, respectively. Among all QTLs, $q C u 4-2$ had the largest single effect (10.4\% of the phenotypic variance), $q \mathrm{Cu} 7 \mathrm{had}$ the lowest single effect $(2.8 \%$ of the phenotypic variance). The positive alleles (increasing trace metal element concentrations) at 16 QTLs except $q C d 2, q C u 7, q F e 7, q M n 7, q Z n 1-1$ and $q Z n 4$ were inherited from the female parent Zhenshan 97 B (ZS97B). These QTLs distributed on chromosomes 1, 2, 4, 5, 7, 8, 10 and 11. Six QTLs were clustered in 1, 4 and 7 chromosomal regions. Especially, $q C d 5$ was a novel QTL regulated low Cd accumulation in rice. The identification of QTLs provides good candidates for fine mapping and cloning, and could be utilized to improve rice safe and nutritional quality by MAS. (C) 2018 Friends Science Publishers
\end{abstract}

Keywords: Trace metal element concentrations; Recombinant inbred lines; QTLs; Mapping; Rice

\section{Introduction}

Iron $(\mathrm{Fe})$, manganese $(\mathrm{Mn})$, copper $(\mathrm{Cu})$ and zinc $(\mathrm{Zn})$ are essential trace mineral elements to maintain the health of human being (Zheng, 1999). The appropriate intake of trace mineral elements is beneficial to human and animals health, mineral deficiencies harmed human beings health and development with symptoms, such as mental retardation immune dysfunction (Stein, 2010). Trace mineral elements couldn't be biosynthetic in vivo, and staple foods are identified as a valid and safe approach to supplement them. Researchers considered that bio-augmentation can improve the mineral nutrients content in crops (Welch and Graham, 2002). Cadmium (Cd) is highly toxic trace metal element to human beings and it could easily enter food chains from polluted crops (Tezuka et al., 2010). With the development of mining and modern industry, Cd pollution is becoming more and more serious, particularly for paddy fields irrigated with Cd-contaminated water, and crops planted in the fields assimilate and accumulate $\mathrm{Cd}$, it may lead destructive consequences for human health (Tezuka et al., 2010). Therefore, crops, especially rice, with low cadmium absorption and accumulation are rush.
Rice, one of the most important food crops, is the staple food for more than half of the world's population and provides a large proportion of mineral nutrients of food in China. Significant genetic variations have been reported for grain trace metal element concentrations in various rice varieties, and genetic analysis has indicated that the genetic components played a major role in determining the grain trace metal element concentration variation, which provides an potential method to breeding new rice varieties with low $\mathrm{Cd}$ concentration and essential mineral elements-rich to resolve above problems (Wu et al., 1999).

In recent years, numerous QTLs have been reported for trace metal elements in rice grain. Jamescr et al. (2007) identified 11 QTLs for mineral nutrients concentrations by using a doubled haploid population derived from the combination of IR64×Azucena. Ishikawa et al. (2005) identified QTLs for Cd concentration on chromosomes 3, 6 and 8 by using CSSLs. Huang et al. (2015) detected 20 QTLs for $\mathrm{Fe}, \mathrm{Zn}, \mathrm{Se}, \mathrm{Cd}$ and $\mathrm{Pb}$ concentrations by using 378 accessions of brown rice. Norton et al. (2010) detected 77 QTLs, (36 for leaves and 41 for grains) for 17 elements concentrations by using introgression lines of Bala×Azucena. Du et al. (2013) detected 32 QTLs for the 7

To cite this paper: Huang, F., X. Wei, J. He, Z. Sheng, G. Shao, J. Wang, S. Tang, S. Xia, Y. Xiao and P. Hu, 2018. Mapping of quantitative trait loci associated with concentrations of five trace metal elements in rice (Oryza sativa). Int. J. Agric. Biol., 20: 554-560 
mineral elements investigated by using a double-haploid population derived from the cross between Chunjiang 06 and TN1. Zhang et al. (2014) detected 134 QTLs associated with the grain concentrations of individual elements by using a recombinant inbred lines and a backcross introgression lines that derived from the cross between Lemont and TeQing. Hu et al. (2016) detected 24 QTLs for mineral element concentrations in brown and milled rice by using backcross inbred lines derived from the cross between Xieqingzao B and Dongxiang wild rice. Mahender et al. (2016) detected 37 QTLs for rice grain mutational traits through transgenic and advanced genomic approaches. Considering people grow rice for mainly eating grains, while the corresponding molecular regulatory mechanism of trace metal elements of $\mathrm{Cd}, \mathrm{Cu}$ and zinc, $\mathrm{Mn}$ and $\mathrm{Fe}$ in brown rice keeps still unclear, therefore, carrying out researches on this aspect of the mechanism are very necessary. According to test design, we planted a set of stable recombinant inbred lines of rice group in different cultural environment, then harvested the grains, and tested the trace metal elements of $\mathrm{Cd}, \mathrm{Cu}$ and zinc, $\mathrm{Mn}$ and $\mathrm{Fe}$ content, finally, combined with relevant molecular map, and mapped of the relevant QTLs, which provided the foundation for subsequent further research.

In this study, we identified 22 QTLs of the concentration of $\mathrm{Cd}, \mathrm{Cu}, \mathrm{Zn}, \mathrm{Mn}$ and $\mathrm{Fe}$ in brown rice using a RIL population with 204 lines derived from the cross between ZS97B, an elite indica maintainer line, and Miyang 46 (MY46), an elite indica three-line restorer, which makes it possible for rice breeders to develop closely linked markers for conducting marker-assisted selection of breeding, and set the stage for the fine mapping and even positional cloning of these QTLs. The identification of QTLs could be utilized to efficient breeding low $\mathrm{Cd}$ concentration rice varieties and mineral elements-rich rice varieties by MAS.

\section{Materials and Methods}

\section{Plant Materials}

An $\mathrm{F}_{13}$ RIL population with 204 lines generated from the cross of ZS97B $\times$ MY46 and parental lines were planted in experimental paddy fields and pots with $\mathrm{Cd}$ stress at China National Rice Research Institute (CNRRI) in Hangzhou, respectively. In FC trial, 10 seedlings of each line per row were transplanted with a spacing of $20.0 \mathrm{~cm}$ between seedlings within a row and $20.0 \mathrm{~cm}$ between each two rows. The plants were watered with agricultural irrigated water and managed as traditional pattern of paddy fields from June to October in 2013. In PC trial, 2 seedlings of each line were transplanted with a spacing of $20.0 \mathrm{~cm}$ between the two seedlings. The plants were grown in a greenhouse and watered daily with tap water to keep the soil soaked in the water from June to October in 2013. Both trials were designed by random zone and repeated three times. At harvest, rice grains of each line were mix harvested and manually threshed in both trials. The concentration of trace metal elements in brown rice and experimental soil were determined with inductively coupled plasma optical emission spectrometry (ICP-OES) after digestion, as described below. The trace metal element concentrations of soil in PC and FC trials are listed in Table 1.

\section{Sample Preparation}

After sun-dried, the rice grains were stored at room temperature for three months, and then $20 \mathrm{~g}$ grains of each line were de-hulled with a testing sheller, after that the brown rice were grinded to powder using a sample grinder and passed through a $0.20 \mathrm{~mm}$ mesh sieve.

\section{Measurement of $\mathrm{Cd}, \mathrm{Cu}, \mathrm{Mg}, \mathrm{Zn}$ and $\mathrm{Fe}$ Concentrations}

About $0.5 \mathrm{~g}$ of rice powder were weighted into a $50 \mathrm{~mL}$ high temperature- and acid-resistant plastic tube and added with $5.0 \mathrm{~mL}$ guaranteed reagent nitric acid $\left(\mathrm{HNO}_{3}\right)$, then these samples were digested with microwave digestion instrument MARS 5 after shaking gently, and next the digestion tubes were heated from room temperature to $120^{\circ} \mathrm{C}$ for $5 \mathrm{~min}$, at $120^{\circ} \mathrm{C}$ for $3 \mathrm{~min}$, and then from $120^{\circ} \mathrm{C}$ to $180^{\circ} \mathrm{C}$ for $6 \mathrm{~min}$, at $180^{\circ} \mathrm{C}$ for $10 \mathrm{~min}$. When the tubes were cooled at $90^{\circ} \mathrm{C}$, taken off their lids and then heated at $150^{\circ} \mathrm{C}$ until about $0.5 \mathrm{~mL}$ solution remained. The digested samples were cooled and diluted to imported centrifugal tubes of 50 $\mathrm{mL}$ with double de-ionized water. Finally, according to the manufacturer's instructions, the concentrations of $\mathrm{Cd}, \mathrm{Cu}$, $\mathrm{Mg}, \mathrm{Zn}$ and $\mathrm{Fe}$ were simultaneously measured by ICP-OES.

\section{Data Analysis}

A total of 256 markers were used to construct a genetic linkage map spanning $1814.7 \mathrm{cM}$ on total 12 chromosomes, with an average interval length of $7.09 \mathrm{cM}$ (Fig. 1). Composite interval mapping analysis of QTL in the RIL population was performed with WinQTLcart 2.5. QTLs were called where their logarithm of the odds (LOD) values exceeded 2.0, and the proportion of phenotypic variation was estimated from the coefficient of determination $\left(\mathrm{R}^{2}\right)$. Parameter settings for the QTL mapping were as described by Matsubara (Matsubara et al., 2008). The QTL was named following the nomenclature recommended by McCouch and CGSNL (McCouch and CGSNL, 2008). Pearson's product-moment correlation coefficients between the traits were determined using SAS software.

\section{Results}

The Traits Performance of ZS97B, MY46 and the RIL Population

ZS97B showed significant higher trait values than MY46 in $\mathrm{Cu}$ and $\mathrm{Mn}$, while showed lower trait values in $\mathrm{Cd}, \mathrm{Fe}$, no significant difference was identified in $\mathrm{Zn}$ concentrations in 
Table 1: Trace metal element concentrations $(\mathrm{mg} / \mathrm{kg})$ of soil in PC and FC trials

\begin{tabular}{llllll}
\hline Trials $\mathrm{Cd}$ & $\mathrm{Cu}$ & $\mathrm{Fe}$ & $\mathrm{Mn}$ & $\mathrm{Zn}$ \\
\hline $\mathrm{PC}$ & $5.88 \pm 0.25$ & $38.06 \pm 2.89$ & $236.78 \pm 14.60$ & $58.71 \pm 2.20$ & $23.90 \pm 0.86$ \\
$\mathrm{FC}$ & $0.53 \pm 0.05$ & $35.53 \pm 1.61$ & $114.86 \pm 21.70$ & $41.54 \pm 5.07$ & $27.15 \pm 1.46$ \\
\hline $\begin{array}{l}\text { PC and FC } \\
\text { respectively }\end{array}$
\end{tabular}

Table 2: Trace metal element concentrations $(\mathrm{mg} / \mathrm{kg})$ of ZS97B, MY46 and the RIL population

\begin{tabular}{llllllll}
\hline \multirow{2}{*}{$\begin{array}{l}\text { Trace } \\
\text { metal } \\
\text { elements }\end{array}$} & Trails & \multicolumn{3}{c}{ Parents } & \multicolumn{4}{c}{ RIL lines } \\
\cline { 3 - 8 } & & & ZS97B MY46 Mean \pm SD & Min-Max & Skew & Kurt \\
\hline Cd & PC & 1.82 & 2.94 & $2.79 \pm 0.97$ & $0.95-6.73$ & 0.935 & 0.9822 \\
& FC & 0.13 & 0.24 & $0.15 \pm 0.05$ & $0.05-0.31$ & 0.523 & -0.0546 \\
$\mathrm{Cu}$ & PC & 5.82 & 4.5 & $2.78 \pm 1.89$ & $2.63-6.65$ & 0.4209 & 0.2423 \\
& FC & 4.99 & 3.95 & $4.57 \pm 0.74$ & $2.79-6.51$ & 0.2492 & -0.2246 \\
Fe & PC & 7.92 & 9.33 & $8.54 \pm 2.84$ & $2.56-16.81$ & -0.2534 & -0.2489 \\
& FC & 13.84 & 9.64 & $10.42 \pm 1.39$ & $7.87-15.55$ & 0.9398 & 1.3033 \\
Mn & PC & 41.66 & 31.42 & $32.3 \pm 6.30$ & $21.19-32.28$ & 0.8108 & 0.7806 \\
& FC & 40.03 & 28.14 & $27.09 \pm 4.21$ & $16.04-39.93$ & 0.5536 & 0.0597 \\
Zn & PC & 26.81 & 26.93 & $27.92 \pm 5.23$ & $18.55-49.76$ & 1.1596 & 2.1708 \\
& FC & 25.26 & 24.74 & $21.78 \pm 2.87$ & $15.90-31.68$ & 0.7752 & 0.8144 \\
\hline PC
\end{tabular}

$\mathrm{PC}$ and FC represent pot cultivation and paddy field cultivation

PC trial; ZS97B had higher $\mathrm{Cu}, \mathrm{Fe}, \mathrm{Mn}, \mathrm{Zn}$ concentration than MY46, but lower Cd concentration in FC trial. Except $\mathrm{Fe}$, the other four trace metal elements concentrations were higher in PC trial than in FC trial (Table 2).

All of these traits showed continuous distribution and transgressive segregation, which suggests that these traits are controlled by QTLs. The absolute value of kurtosis and skewness of these five mineral elements were almost less than one, which indicated the frequency distribution of these traits showed normal variation (Table 2 and Fig. 1).

\section{Correlation Analysis among Different Trace Metal Element Concentrations}

Simple correlation analysis showed that $\mathrm{Cd}$ and $\mathrm{Cu}, \mathrm{Cu}$ and $\mathrm{Fe} / \mathrm{Mn} / \mathrm{Zn}, \mathrm{Fe}$ and $\mathrm{Mn} / \mathrm{Zn}, \mathrm{Mn}$ and $\mathrm{Zn}$ concentrations in brown rice of the RIL population were significant positive correlated in both trials, which implied accumulation and increase of one kind of trace metal element would cause accumulation and increase of other trace metal elements with synergistic effect. In PC trial, except $\mathrm{Cd}$ and $\mathrm{Mn}$ concentrations, the other trace metal element concentrations had significant positive correlated with each other. In FC trial, except $\mathrm{Cd}$ and $\mathrm{Fe} / \mathrm{Mn} / \mathrm{Zn}$ concentrations, the other trace metal element concentrations had significant positive correlated with each other (Table 3).

\section{QTLs Analysis of Trace Metal Element Concentrations in Brown Rice}

The interval QTL mapping of five trace metal elements concentrations in brown rice identified 22 QTLs, including 9 QTLs in PC trail and 13 QTLs in FC trial, respectively.
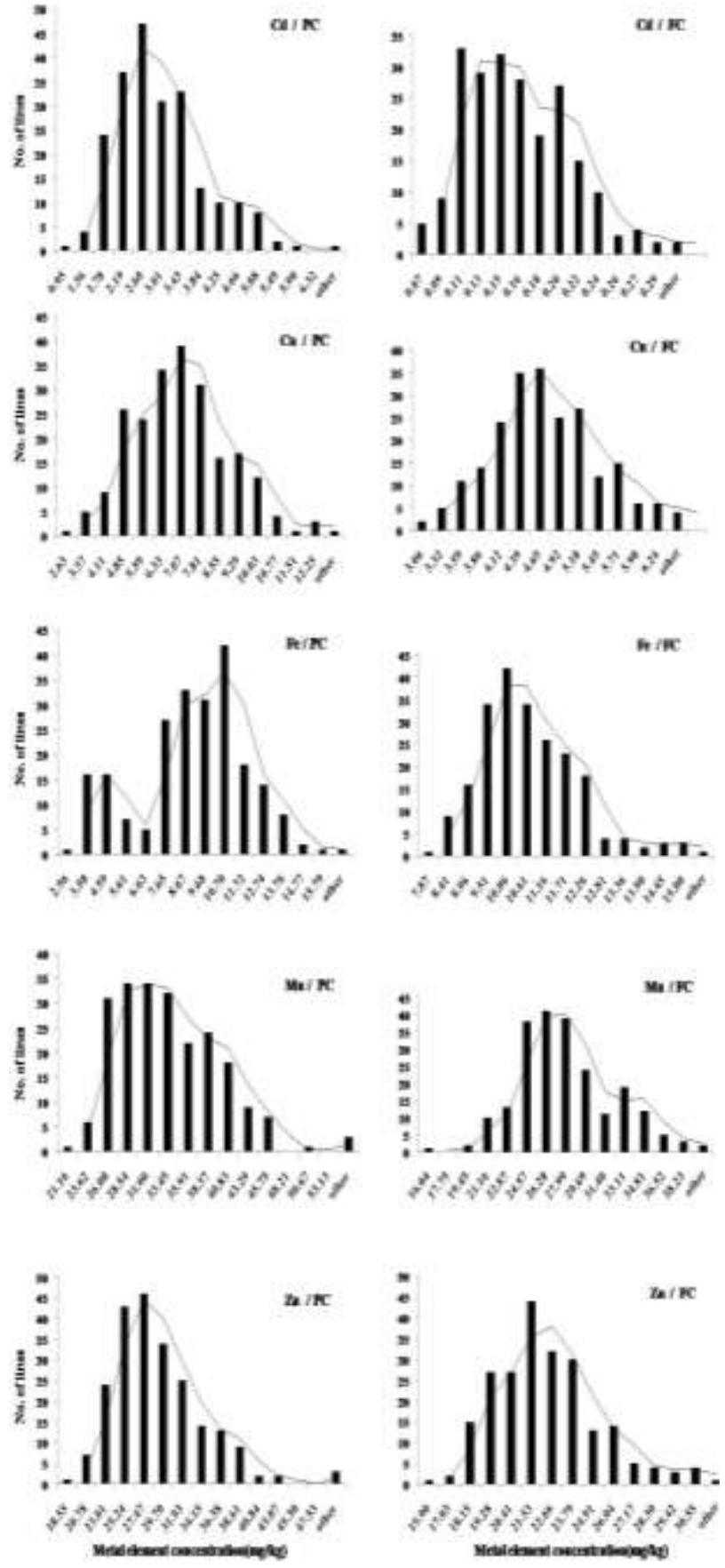

Fig. 1: The phenotypic frequency distribution of $\mathrm{Cd}, \mathrm{Cu}$, $\mathrm{Fe}, \mathrm{Mn}$ and $\mathrm{Zn}$ concentrations $(\mathrm{mg} / \mathrm{kg})$ in brown rice in $\mathrm{PC}$ and FC trials, respectively; $\mathrm{PC}$ and FC represent pot cultivation and paddy field cultivation

These QTLs distributed on rice chromosome 1, 2, 4, 5, 7, 8 and 11. Except $q C d 5$, the other QTLs for trace metal element concentrations in brown rice weren't repeatable detected. The phenotypic variance explained by a single QTL ranged as $4.6-9.9 \%$ and $2.8-10.4 \%$ in PC and FC trials, respectively (Table 4 and Fig. 2). 
QTLs Mapping for Concentrations of Trace Metal Elements in Rice / Int. J. Agric. Biol., Vol. 20, No. 3, 2018
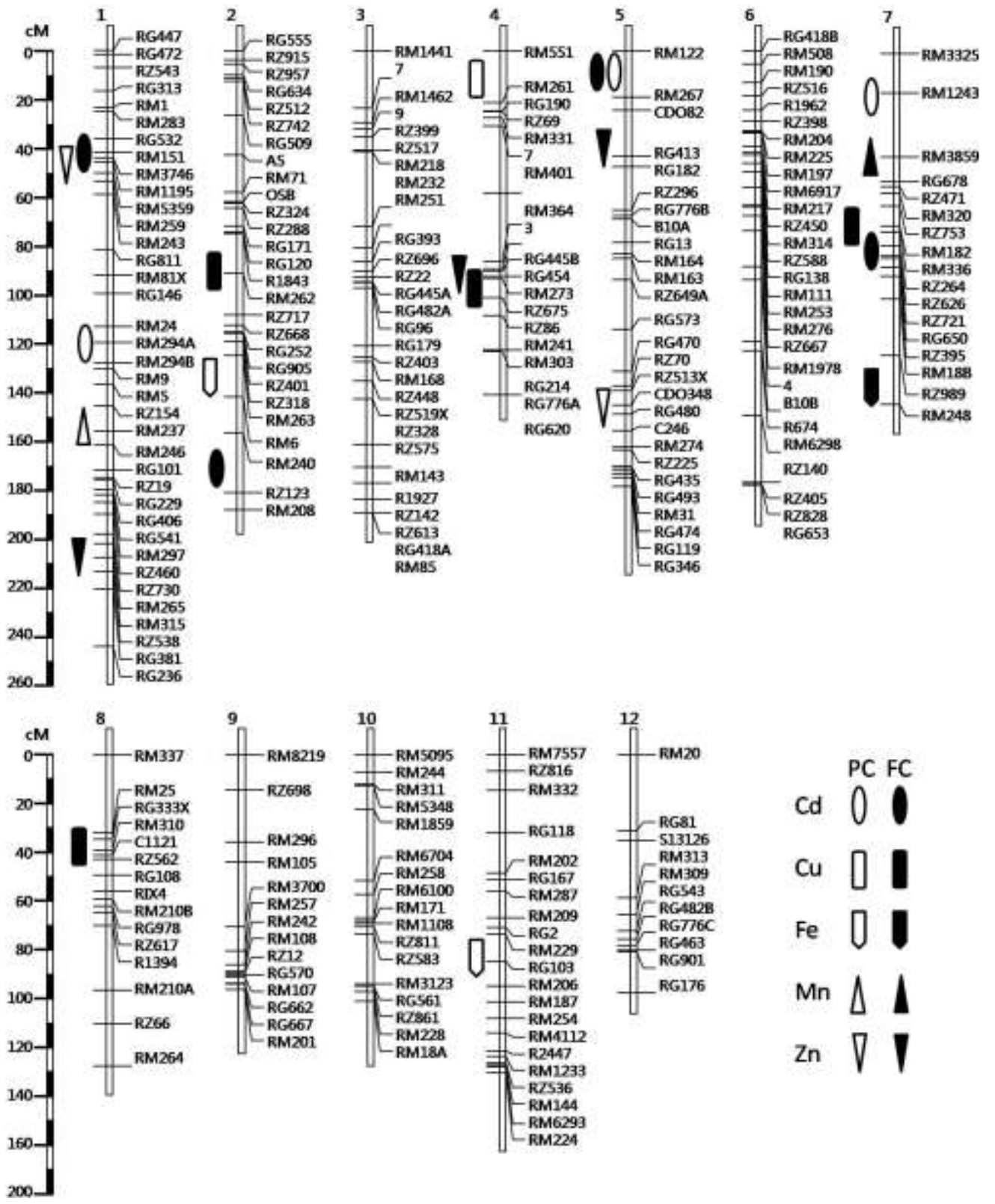

Fig. 2: Chromosomal distribution of QTLs for $\mathrm{Cd}, \mathrm{Cu}, \mathrm{Fe}, \mathrm{Mn}$ and $\mathrm{Zn}$ concentrations in brown rice in $\mathrm{PC}$ and $\mathrm{FC}$ trials, respectively; $\mathrm{PC}$ and FC represent pot cultivation and paddy field cultivation

QTLs for Cd: Seven QTLs for Cd contents were detected, including one for both trials. In PC trial, $q C d 1-1, q C d 5$, $q C d 7-1$ were detected. The phenotypic variations caused by each QTL were around 5.9-9.9\%, respectively. The positive alleles at these QTLs loci were inherited from ZS97B with low $\mathrm{Cd}$ concentration in brown rice. In FC trail, $q C d 1-2$, $q C d 2, q C d 5, q C d 7-2$ were identified, explaining $4.8-6.2 \%$ of the phenotypic variance, respectively. Except $q C d 2$, the positive allele of $q C d 1-2, q C d 5$ and $q C d 7-2$ were inherited from ZS97B. The $q C d 5$ were detected in both trials.

QTLs for Cu: Five QTLs for $\mathrm{Cu}$ concentration were identified. In PC trail, only $q C u 4-1$ was detected, explaining about $5.4 \%$ of the phenotypic variance. The positive allele of $q C u 4-1$ derived from ZS97B. The other four QTLs $q C u 2$, $q \mathrm{Cu} 4-2, q \mathrm{Cu} 7$ and $q \mathrm{Cu} 8$ were identified in $\mathrm{FC}$ trail, explained $2.8-10.6 \%$ of the phenotypic variance and had additive value ranging from 2.12 to 5.49 . The positive alleles all derived from ZS97B except $q C u 7$.

QTLs for Fe: Three QTLs for Fe concentration were detected. In PC trail, $q \mathrm{Fe} 2$ and $q \mathrm{Fe} 11$ were detected, which explained about $7.5 \%$ and $4.6 \%$ of the phenotypic variance, respectively. The positive alleles of $q \mathrm{Fe} 2$ and $q \mathrm{Fe} 11$ both derived from ZS97B. In FC trail, only one QTL, $q F e 7$, was detected, accounting for about $5.3 \%$ of the phenotypic 
Table 3: Correlation coefficient for trace metal element concentrations in the RIL population

\begin{tabular}{llllll}
\hline Trace metal elements & Trails & $\mathrm{Cu}$ & $\mathrm{Fe}$ & $\mathrm{Mn}$ & $\mathrm{Zn}$ \\
\hline $\mathrm{Cd}$ & $\mathrm{PC}$ & $0.302^{* *}$ & $0.154^{*}$ & 0.118 & $0.245^{* *}$ \\
& $\mathrm{FC}$ & $0.321^{* *}$ & -0.052 & 0.057 & 0.01 \\
$\mathrm{Cu}$ & $\mathrm{PC}$ & & $0.220^{* *}$ & $0.442^{* *}$ & $0.661^{* *}$ \\
& $\mathrm{FC}$ & & $0.157^{*}$ & $0.140^{*}$ & $0.322^{* *}$ \\
$\mathrm{Fe}$ & $\mathrm{PC}$ & & & $0.193^{* *}$ & $0.351^{* *}$ \\
& $\mathrm{FC}$ & & & $0.300^{* *}$ & $0.386^{* *}$ \\
$\mathrm{Mn}$ & $\mathrm{PC}$ & & & & $0.505^{* *}$ \\
& $\mathrm{FC}$ & & & & $0.537^{* *}$ \\
\hline PC and
\end{tabular}

$\mathrm{PC}$ and FC represent pot cultivation and paddy field cultivation; *** significant at the level of $0.05,0.01$ respectively

Table 4: QTLs analysis for trace metal element concentrations in brown rice in the RIL population

\begin{tabular}{|c|c|c|c|c|c|c|c|}
\hline Trails & $\begin{array}{l}\text { Trace meta } \\
\text { elements }\end{array}$ & & Chr. & Interval & LOD & A & $\overline{R^{2}}$ \\
\hline \multirow[t]{9}{*}{$\overline{\mathrm{PC}}$} & \multirow[t]{3}{*}{$\mathrm{Cd}$} & $q C d 1-1$ & 1 & RM24-RM5 & 2.91 & 0.2364 & 5.9 \\
\hline & & $q C d 5$ & 5 & RM122-RM267 & 3.98 & 0.2979 & 9.9 \\
\hline & & $q C d 7-1$ & 7 & RM1243-RG678 & 3.88 & 0.2641 & 6.4 \\
\hline & $\mathrm{Cu}$ & $q C u 4-1$ & 4 & RM551-RM261 & 2.03 & 0.442 & 5.4 \\
\hline & \multirow[t]{2}{*}{$\mathrm{Fe}$} & $q F e 2$ & 2 & RM263-RZ123 & 3.2 & 0.7879 & 7.5 \\
\hline & & qFel1 & 11 & RG103-RM4112 & 2.15 & 0.6204 & 4.6 \\
\hline & $\mathrm{Mn}$ & $q M n 1$ & 1 & RZ154-RM264 & 2.6 & 1.5899 & 6.4 \\
\hline & \multirow[t]{2}{*}{$\mathrm{Zn}$} & $q Z n 1-1$ & 1 & RG532-RM5359 & 3.56 & -1.356 & 6.9 \\
\hline & & $q Z n 5-1$ & 5 & RG470-C246 & 3.15 & 1.3474 & 6.7 \\
\hline \multirow[t]{13}{*}{ FC } & \multirow[t]{4}{*}{$\mathrm{Cd}$} & $q C d 1-2$ & 1 & RM283-RM259 & 2.67 & 0.0114 & 4.8 \\
\hline & & $q C d 2$ & 2 & RM240-RZ123 & 2.35 & -0.0131 & 6.2 \\
\hline & & $q C d 5$ & 5 & RM122-RM267 & 2.54 & 0.0127 & 5.3 \\
\hline & & $q C d 7-2$ & 7 & RZ753-RZ626 & 3.55 & 0.013 & 5.9 \\
\hline & \multirow[t]{4}{*}{$\mathrm{Cu}$} & $q \mathrm{Cu} 2$ & 2 & R1843-RZ717 & 2.12 & 0.163 & 3.9 \\
\hline & & $q C u 4-2$ & 4 & RZ86-RG214 & 5.49 & 0.2558 & 10.6 \\
\hline & & $q \mathrm{Cu} 7$ & 7 & RM320-RM182 & 2.47 & -0.1608 & 2.8 \\
\hline & & $q \mathrm{Cu} 8$ & 8 & RM25-RM310 & 2.18 & 0.1442 & 3.8 \\
\hline & $\mathrm{Fe}$ & $q \mathrm{Fe} 7$ & 7 & RZ989-RM248 & 2.1 & -0.3193 & 5.3 \\
\hline & $\mathrm{Mn}$ & $q M n 7$ & 7 & RM1243-RG678 & 2.78 & -1.0979 & 5.1 \\
\hline & \multirow[t]{3}{*}{$\mathrm{Zn}$} & $q Z n 1-2$ & 1 & RZ730-RZ538 & 2.12 & 0.585 & 4.4 \\
\hline & & $q Z n 4$ & 4 & RM3643-RM241 & 2.48 & -0.6165 & 4.4 \\
\hline & & $q Z n 5-2$ & 5 & CDO82-RG182 & 3.09 & 0.7306 & 6.4 \\
\hline
\end{tabular}

PC and FC represent pot cultivation and paddy field cultivation, respectively; A represents additive effect. $\mathrm{R} 2$ represents the proportion of phenotypic variance explained by each given QTL

variance. The positive alleles derived from MY46.

QTLs for Mn: Two QTLs for Mn concentration were identified. In PC trail, one QTL, $q M n 1$, was detected, explaining about $6.4 \%$ of the phenotypic variance. The positive alleles of $q M n l$ derived from ZS97B. In FC trail, one QTL, $q M n 7$, was detected, accounting for about $5.1 \%$ of the phenotypic variance. The positive alleles of $q M n 7$ derived from MY46.

QTLs for Zn: Five QTLs were detected for Zn concentration. In PC trail, $q Z n 1-1$ and $q Z n 5-1$ were detected, explaining $6.9 \%$ and $6.7 \%$ of the phenotypic variance, respectively. The positive allele of $q Z n l-1$ derived from MY46, while $q Z n 5-1$ derived from ZS97B. In FC trail, $q Z n 1-2, q Z n 4$ and $q Z n 5-2$ were detected, explaining the phenotypic variances about $4.4-6.4 \%$, respectively. The positive allele of $q Z n 1-2$ and $q Z n 5-2$ derived from ZS97B, while $q Z n 4$ derived from MY46.

\section{Discussion}

Some studies revealed that there was interaction among $\mathrm{Cd}$, $\mathrm{Cu}, \mathrm{Fe}, \mathrm{Mn}$ and $\mathrm{Zn}$ in the process of absorbing and accumulating in rice (Jamescr et al., 2007; Shao et al., 2007; Ishimaru et al., 2012). In our study, the absorption and accumulation of 5 trace metal elements in rice grain presented typical characteristics of quantitative traits, affected by soil environment and there was significant positive correlation between each other. Such as Fe and Zn, $\mathrm{Mn}$ and $\mathrm{Zn}$ concentrations in brown rice were significant positive correlated in both PC and FC trials, which implied accumulation and increase of one kind of trace metal element would cause accumulation and increase of other trace metal elements with synergistic effect, and it was similar to some other researches' conclusions (Vert et al., 2001; Jamescr et al., 2007).

A slight increase of mineral element concentrations and a decrease of $\mathrm{Cd}$ concentration in rice grain would efficiently alleviate ongoing human mineral deficiencies and $\mathrm{Cd}$ contaminated rice threatens (Ishimaru et al., 2012). Therefore, making the genetic variation and mechanism of trace metal element concentrations in rice grains clear is essential for improving safe and nutritional quality in rice breeding. The concentrations of trace metal element in rice grain are typical quantitative traits and their heredity are complicated. In this study, we identified 22 QTLs for $\mathrm{Cd}, \mathrm{Cu}, \mathrm{Fe}, \mathrm{Mn}$ and $\mathrm{Zn}$ concentrations in brown rice, including one for $\mathrm{PC}$ and $\mathrm{FC}$ trials, 9 for $\mathrm{PC}$ trial only, and 13 for $\mathrm{FC}$ trial only, using an $\mathrm{F}_{13}$ RIL population derived from the cross of ZS97B $\times$ MY46. These QTLs distributed on chromosomes 1, 2, 4, 5, 7, 8, 10 and 11. Among these 22 QTLs, $q \mathrm{Cu} 4-2$ had the largest single effect (10.4\% of the phenotypic variance), $q \mathrm{Cu} 7$ had the lowest single effect (2.8\% of the phenotypic variance). The positive alleles (increasing trace metal element concentrations) at 16 QTLs except $q \mathrm{Cd} 2, q \mathrm{Cu} 7, q \mathrm{Fe} 7, q \mathrm{Mn} 7$, $q Z n 1-1$ and $q Z n 4$ were inherited from ZS97B.

In spite of quantitative trait heredity affected by external environment, those QTLs with high genetic ability could be repeatedly detected. In our study, nine of the QTLs detected were located in genomic regions, where QTLs for trace metal element concentrations of the same element had been reported, including two of the five QTLs for Cd concentration, three of the five QTLs for Cu concentration, one of the three QTLs for Fe concentration, two of the five QTLs for Mn concentration, one of the five QTLs for Zn concentration. For Cd, $q C d 2$ corresponded to a QTL for $\mathrm{Cd}$ concentration and $q G C d 2$ reported by Ueno and Ishikawa (Ueno et al., 2009; Ishikawa et al., 2010), qCd7-1 overlapped with qGCd7, $q G d T 7$ and $q S C d 7$ identified by Ishikawa (Ueno et al., 2009; Ishikawa et al., 2010; Tezuka et al., 2010), respectively; and $q C d 7-2$ co-located with $q C D C N 7$ reported by Shen (Shen et al., 2008). For $\mathrm{Cu}, q C u 2$ co-located with $q C U-2$ reported by $\mathrm{Lu}(\mathrm{Lu}$ et al., 2008), $q \mathrm{Cu} 4-1$ overlapped with $q \mathrm{Cu} 4$ identified by Zhang and $\mathrm{Hu}$ (Zhang et al., 2014; Hu et al., 2016), and $q C u 8$ corresponded 
to $q S C u 8$ reported by Ishikawa (Ishikawa et al., 2010). For $\mathrm{Fe}, q \mathrm{Fe} 7$ corresponded to a QTL for Fe concentration reported by Zhang (Zhang et al., 2014). For Mn, qMnl corresponded to $q G M n 1$ and $q M n 1$ identified by Ishikawa and $\mathrm{Hu}$ (Ishikawa et al., 2010; $\mathrm{Hu}$ et al., 2016), and $q M n 7$ overlapped with $q G M n 7$ reported by Ishikawa (Ishikawa et al., 2010). For Zn, qZn5-1 corresponded to a QTL for Zn concentration reported by Zhang (Zhang et al., 2014). These QTLs could be considered to have been consistently detected in different environments and genetic backgrounds.

At present, many of the functional genes involved in absorption and transportation of trace metal elements in rice grains have been cloned and characterized. The OsNRAMP5, OsHMA3, OsHMA2, OsLCT1 and LCD regulated the uptake, transport and accumulation of $\mathrm{Cd}$ in rice (Ueno et al., 2010; Shimo et al., 2011; Uraguchi et al., 2011; Ishimaru et al., 2012; Sasaki et al., 2012; SatohNagasawa et al., 2012; Takahashi et al., 2012). The OsNRAMP1, OsFER2, OsYSL2, OsYSL15, OsYSL18, OsIRT1 and OsIRT2 contributed to transporting of Fe in rice (Curie et al., 2000; Bughio et al., 2002; Koike et al., 2004; Ishimaru et al., 2006; Nakanishi et al., 2006; Inoue et al., 2009; Aoyama et al., 2009; Takahashi et al., 2011; Paul et al., 2012). The OsYSL2, OsYSL6 and OsNRAMP5 regulated to transporting of $\mathrm{Mn}$ in rice (Ishimaru et al., 2010; Sasaki et al., 2011; Ishimaru et al., 2012). The OsZIP3 and OsZIP4 contributed to Zn transport (Ishimaru et al., 2005; Yang et al., 2009). Our study revealed the OsNRAMP5, OsNRAMP1 and OsHMA3 genes were located in the $q C d 7-1$ region, the OsYSL2 and OsYSL15 genes were located in the $q F e 2$ region, the OsYSL18 gene was located in the $q Z n 1-2$ region and the OsZIP3 gene was located in the $q C u 4-2$ region, which implied there were some genetic locus regulated trace metal elements uptake and accumulation in ZS97B. On the basis of the QTLs detected repeatedly in different years, environments and genetic backgrounds, developing corresponding molecular markers, using MAS to select some special traits in rice would promote the process of rice breeding. Here, we identified a number of QTLs in different environments, and there were some cloned genes related to trace metal element accumulation in the interval of some detected QTLs. Therefore, we could conducted fine-mapping and cloning of above QTLs, then develop relevant functional molecular markers, and use these makers to efficiently select genes derived from ZS97B regulated trace metal element concentrations in rice breeding, at last efficiently develop safe and nutritional rice new varieties.

Clustering of QTLs for related traits also were found in our study, which was similar to some other studies (Shen et al., 2008; Zhang et al., 2014; Hu et al., 2016). Six of the QTLs identified in this study were located in three clusters distributed on three chromosomes. Two QTLs, $q C d 1-2$ and $q Z n 1-1$, were located in the cluster on chromosomes 1. Another two QTLs, $q C u 4-2$ and $q Z n 4$, were located in the cluster on chromosomes 4 (Fig. 1). In one region, $q C d 7-2$ was clustered with $q \mathrm{Cu} 7$ on chromosomes 7 , which have been reported (Shen et al., 2008). To molecular breeding, pleiotropy (one gene affecting multiple phenotypes) was meaningful to fine-mapping and cloning of clustered QTLs. On one hand, we need to know the number of related characters between themselves. On the other hand, we need to understand correlation between quantitative traits. Furthermore, we may use molecular makers close linkage to these QTLs to breed new rice varieties by MAS, and simultaneously improve multiple traits in rice.

\section{Conclusion}

Trace mental element concentrations in rice are complex quantitative traits. Further studies are needed to fine mapping and clone these novel QTLs for $\mathrm{Fe}, \mathrm{Mn}, \mathrm{Cu}, \mathrm{Zn}$ and $\mathrm{Cd}$ concentrations in brown rice in the future, and which also could be utilized to improve rice safe and nutritional quality by MAS.

\section{Acknowledgements}

We thank Prof. Jieyun Zhuang (China National Rice Research Institute) for providing molecular genetic map and seeds of the RIL population, and Prof. Guosheng Shao for providing help to measure trace metal element concentrations. This work was supported by the National Key Research and Development Program of China (2016YFD0101801), the National S\&T Major Project of China (2016ZX08001006) and Hunan Agricultural Science and Technology Innovation Fund (2017XC10).

\section{References}

Aoyama, T., T. Kobayashi, M. Takahashi, S. Nagasaka, K. Usuda, Y. Kakei, Y. Ishimaru, H. Nakanishi, S. Mori and N.K. Nishzawa, 2009. OsYSL18 is a rice iron (III)- deoxymugineic acid transporter specifically expressed in reproductive organs and phloem of lamina joints. Plant Mol. Biol., 70: 681-692

Bughio, N., H. Yamaguchi, N.K. Nishizawa, H. Nakanishi and S. Mori, 2002. Cloning an iron-regulated metal transporter from rice. J. Exp. Bot., 53: 1677-1682

Curie, C., J.M. Alonso, J.M. Le, J.R. Ecker and J.F. Briat, 2000. Involvement of NRAMP1 from Arabidopsis thaliana in iron transport. Biochem. J., 347: 749-755

Du, J., D. Zeng, B. Wang, Q. Qian, S. Zheng and H.Q. Ling, 2013. Environmental effects on mineral accumulation in rice grains and identification of ecological specific QTLs. Environ. Geochem. Health, 35: 161-170

Hu, B.L., D.R. Huang, Y.Q. Xiao, Y.Y. Fan, D.Z. Chen and J.Y. Zhuang, 2016. Mapping QTLs for mineral element contents in brown and milled rice using an Oryza sativa $\times O$ rufipogon backcross inbred line population. Cereal Res. Commun., 44: 1-12

Huang, Y., C. Sun, J. Min, Y. Chen, C. Tong and J. Bao, 2015. Association mapping of quantitative trait loci for mineral element contents in whole grain rice (Oryza sativa L.). J. Agric. Food Chem., 63: 1088510892

Inoue, H., T. Kobayashi, T. Nozoye, Y. Kakei, K. Suzuki, M. Nakazono, H. Nakanishi, S. Mori and N.K. Nishizawa, 2009. Rice OsYSL15 is an iron-regulated iron (III)- deoxymugineic acid transporter expressed in the roots and is essential for iron uptake in early growth of the seedlings. J. Biol. Chem., 284: 3470-3479 
Ishikawa, S., N. Ae and M. Yano, 2005. Chromosomal regions with quantitative trait loci controlling cadmium concentration in brown rice (Oryza sativa). New Phytol., 168: 345-350

Ishikawa, S., T. Abe, M. Kuramata, M. Yamaguchi, T. Ando, T. Yamamoto and M. Yano, 2010. A major quantitative trait locus for increasing cadmium-specific concentration in rice grain is located on the short arm of chromosome 7. J. Exp. Bot., 61: 923-934

Ishimaru, Y., R. Takahashi, K. Bashir, H. Shimo, T. Senoura, K. Sugimoto, K. Ono, M. Yano, S. Ishikawa, T. Arao, H. Nakanishi and N.K. Nishizawa, 2012. Characterizing the role of rice NRAMP5 in manganese, iron and cadmium transport. Sci. Rep., 2: 1-8

Ishimaru, Y., H. Masuda, K. Bashir, H. Inoue, T. Tsukamoto, M. Takahashi, H. Nakanishi, N. Aoki,T. Hirose, R. Ohsugi and N.K. Nishizawa, 2010. Rice metal-nicotianamine transporter, OsYSL2, is required for the long-distance transport of iron and manganese. Plant J., 62: 379-390

Ishimaru, Y., M. Suzuki, T. Tsukamoto, K. Suzuki, M. Nakazono, T. Kobayashi, Y. Wada, S. Watanabe, S. Matsuhashi, M. Takahashi, H. Nakanishi, S. Mori and N.K. Nishizawa, 2006. Rice plants take up iron as an $\mathrm{Fe}^{3+}$-phytosiderophore and as $\mathrm{Fe}^{2+}$. Plant J., 45: 335-346Ishimaru, Y., M. Suzuki, T. Kobayashi, M. Takahashi, H. Nakanishi, S. Mori and N.K. Nishizawa, 2005. OsZIP4, a novel zincregulated zinc transporter in rice. J. Exp. Bot., 56: 3207-3214

Jamescr, S., H. Baolam, W. Rossm, C. Eunyoung and G. Robind, 2007. Quantitative trait loci for phytate in rice grain and their relationship with grain micronutrient content. Euphytica, 154: 289-294

Koike, S., H. Inoue, D. Mizuno, M. Takahashi, H. Nakanishi, S. Mori and N.K. Nishizawa, 2004. OsYSL2 is a rice metal-nicotianamine transporter that is regulated by iron and expressed in the phloem. Plant J., 39: 415-424

Lu, K., L. Li, X. Zheng, Z. Zheng, T. Mou and Z. Hu, 2008. Quantitative trait loci controlling $\mathrm{Cu}, \mathrm{Ca}, \mathrm{Zn}, \mathrm{Mn}$ and $\mathrm{Fe}$ content in rice grains. $J$. Genet., 87: 305-310

Mahender, A., A. Anandan, S.K. Pradhan and E. Pandit, 2016. Rice grain nutritional traits and their enhancement using relevant genes and QTLs through advanced approaches. Springer Plus, 5: 2086

Matsubara, K., I. Kono, K. Hori, Y. Nonoue, N. Ono, A. Shomura, T. Mizubayashi, S. Yamamoto, U. Yamanouchi, K. Shirasawa, T. Nishio and M. Yano, 2008. Novel QTLs for photoperiodic flowering revealed by using reciprocal backcross inbred lines from crosses between japonica rice cultivars. Theor. Appl. Genet., 117: 935-945

McCouch, S.R. and CGSNL (Committee on Gene Symbolization, Nomenclature and Linkage, Rice Genetics Cooperative), 2008. Gene nomenclature system for rice. Rice, 1: 72-84

Nakanishi, H., I. Ogawa, Y. Ishimaru, S. Mori and N.K. Nishizawa, 2006. Iron deficiency enhances cadmium uptake and translocation mediated by the $\mathrm{Fe}^{2+}$ transporters OsIRT1 and OsIRT2 in rice. Soil Sci. Plant Nutr., 52: 464-469

Norton, G.J., C.M. Deacon, L.Z. Xiong, S.Y. Huang, A.A. Meharg and A.H. Price, 2010. Genetic mapping of the rice ionome in leaves and grain: identification of QTLs for 17 elements including arsenic, cadmium, iron and selenium. Plant Soil, 329: 139-153

Paul, S., N. Ali, D. Gayen, S.K. Datta and K. Datta, 2012. Molecular breeding of Osfer2 gene to increase iron nutrition in rice grain. G.M. Crops Food, 3: 310-316

Sasaki, A., N. Yamaji, K. Yokosho and J.F. Ma, 2012. Nramp5 is a major transporter responsible for manganese and cadmium uptake in rice. Plant Cell, 24: 2155-2167

Sasaki, A., N. Yamaji, J. Xia and J.F. Ma, 2011. OsYSL6 is involved in the detoxification of excess manganese in rice. Plant Physiol., 157: $1832-1840$
Satoh-Nagasawa, N., M. Mori, N. Nakazawa, T. Kawamoto, Y. Nagato, K. Sakurai, H. Takahashi, A. Watanabe and H. Akagi, 2012. Mutations in rice (Oryza sativa) heavy metal ATPase 2 (OsHMA2) restrict the translocation of zinc and cadmium. Plant Cell Physiol., 53: 213224

Shao, G.S., M.X. Chen, W.X. Wang, R.X. Mou and G. Zhang, 2007. Iron nutrition affects cadmium accumulation and toxicity in rice plants. Plant Growth Regul., 53: 33-42

Shen, X.H., L.Y. Cao, G.S. Shao, X.D. Zhan, S.G. Chen, W.M. Wu and S.H. Cheng, 2008. QTL Mapping for the content of five trace elements in brown rice. Mol. Plant Breed., 6: 1061-1067

Shimo, H., Y. Ishimaru, G. An, T. Yamakawa, H. Nakanishi and N.K. Nishizawa, 2011. Low cadmium (LCD), a novel gene related to cadmium tolerance and accumulation in rice. J. Exp. Bot., 62: 5727 5734

Stein, A.J., 2010. Global impacts of human mineral malnutrition. Plant Soil, 335: 133-154

Takahashi, R., Y. Ishimaru, H. Shimo, Y. Ogo, T. Senoura, N.K. Nishizawa and H. Nakanishi, 2012. The OsHMA2 transporter is involved in root-to-shoot translocation of $\mathrm{Zn}$ and $\mathrm{Cd}$ in rice. Plant Cell Environ., 35: 1948-1957

Takahashi, R., Y. Ishimaru, T. Senoura, H. Shimo, S. Ishikawa, T. Arao, H. Nakanishi and N.K. Nishizawa, 2011. The OsNRAMP1 iron transporter is involved in Cd accumulation in rice. J. Exp. Bot., 62 4843-4850

Tezuka, K., H. Miyadate, K. Katou, I. Kodama, S. Matsumoto, T. Kawamoto, S. Masaki, H. Satoh, M. Yamaguchi, K. Sakurai, H. Takahashi, N. Satoh-Nagasawa, A. Watanabe, T. Fujimura and H. Akagi, 2010. A single recessive gene controls cadmium translocation in the cadmium hyper accumulating rice cultivar Cho-Ko-Koku. Theor. Appl. Genet., 120: 1175-1182

Ueno, D., N. Yamaji, I. Kono, C.F. Huang, T. Ando, M. Yano and J.F. Ma, 2010. Gene limiting cadmium accumulation in rice. Proc. Natl. Acad. Sci. USA, 107: 16500-16505

Ueno, D., I. Kono, K. Yokosho, T. Ando, M. Yano and J.F. Ma, 2009. A major quantitative trait locus controlling cadmium translocation in rice (Oryza sativa). New Phytol., 182: 644-653

Uraguchi, S., T. Kamiya, T. Sakamoto, K. Kasia, Y. Sato, Y. Nagamura, A. Yoshida, J. Kyozuka, S. Ishikawa and T. Fujiwara, 2011. Lowaffinity cation transporter (OsLCT1) regulates cadmium transport into rice grains. Proc. Natl. Acad. Sci. USA, 108: 20959-20964

Vert, G., J.F. Briat and C. Curie, 2001. Arabidopsis IRT2 gene encodes a root-periphery iron transporter. Plant J., 26: 181-189

Welch, R.M. and R.D. Graham, 2002. Breeding crops for enhanced micronutrient content. Plant Soil, 245: 205-214

Wu, Q.T., L. Chen and G.S. Wang, 1999. Differences on Cd uptake and accumulation among rice cultivars and its mechanism. Acta Ecol. Sin., 19: 104-107

Yang, X., J. Huang, Y. Jiang and H.S. Zhang, 2009. Cloning and functional identification of two members of the ZIP (Zrt, Irt-like protein) gene family in rice (Oryza sativa L.). Mol. Biol. Rep., 36: 281-287

Zhang, M., S.R.M. Pinson, L. Tarpley, X.Y. Huang, B. Lahner, E. Yakubova, I. Baxter, M.L. Guerinot and D.E. Salt, 2014. Mapping and validation of quantitative trait loci associated with contents of 16 elements in unmilled rice grain. Theor. Appl. Genet., 127: 137-165

Zheng, J.X., 1999. Functional Foods, Vol. II). China Light Indutsry Press, Beijing, China

(Received 03 June 2017; Accepted 02 November 2017) 